\title{
Optimization of cultural conditions for anaerobically treated distillery effluent bioremediation by an isolate Pseudomonas putida SAG $_{45}$
}

\author{
Anita Rani and Baljeet Singh Saharan* \\ Department of Microbiology, Kurukshetra University, Kurukshetra - 136119 (Haryana), INDIA \\ *Corresponding author. E-mail: Baljeet@DAAD-alumni.de
}

\begin{abstract}
The present study deals with the decolourisation and detoxification of distillery effluent by an isolate $\mathrm{SAG}_{45}$. Soil samples were collected from the affected disposal sites of distillery effluent treatment plant. The isolate showed the highest bioremediation of $79.5 \%$ within 4 days of cultivation in the melanoidin pigment broth. The isolate showed higher decolourisation at $\mathrm{pH} 8.0$ and temperature $37^{\circ} \mathrm{C}$. However, it gives $58.9 \%$ decolourisation with $5 \%(\mathrm{v} / \mathrm{v})$ distillery effluent within 8 days. Toxicity test was also carried out to assess the toxicity of distillery effluent on seed germination.
\end{abstract}

\section{Keywords: Effluent, Decolourisation, Aerobic cultures, Recalcitrant, Toxicity test}

\section{INTRODUCTION}

Alcohol industry is one of the major agro-based industries, which utilize molasses as a raw material for the production of rectified spirit. In addition to rectified spirit, distilleries also produce ethanol. At present 319 distilleries are operating in the country which have the capacity of production of $3.25 \times 10^{9}$ Litres ethanol and also generating $4.04 \times 10^{11}$ Litres of wastewater annually (Pant and Adholeya, 2007). Ethanol manufacture from molasses generates large volumes of high strength wastewater that is of serious environmental concern. The effluent is characterized by extremely high COD $(60,000-$ $\left.100,000 \mathrm{mgL}^{-1}\right), \mathrm{BOD}\left(35,000-60,000 \mathrm{mgL}^{-1}\right)$, low $\mathrm{pH}(4.0-$ 4.5 ), strong odour and dark brown in colour (Satyawali and Balakrishnan, 2007). Expecting a substantial increase in the requirement of ethanol, a large numbers of distilleries would be installed shortly and the production capacity is likely to climb up as the demand for ethanol increases (Naik et al., 2008).

The primary spent wash is generally used in an anaerobic digestion step to utilize its high COD load for fuel (methane) production while reducing its organic load. After conventional aerobic and anaerobic treatments the molasses spent wash becomes biologically inert because of accumulation of nonbiodegradable / recalcitrant compounds. Chandra (1993) identified four bacterial species, predominantly growing in effluent, as Pseudomonas stutzeri, P. acidovorans, Enterobactersp. and Alcaligenes eutrophus. Decolourisation was observed by them up to $60 \%$, with a substantial reduction in BOD and COD as well.

In present investigation colour of effluent was very dark, the light can not penetrate into the waste. Due to the recalcitrant nature of melanoidin, the waste did not support any bacterial growth. The colour removal will solve one of our major problems. Therefore, the main objective in this investigation was to optimize the cultural conditions for an efficient isolate $\mathrm{SAG}_{45}$ for better decolourisation of distillery waste.

\section{MATERIALS AND METHODS}

Media and cultures used: Melanoidin pigment broth (MPB) media having the composition $\mathrm{K}_{2} \mathrm{HPO}_{4}, 0.15 \%$; $\mathrm{MgSO}_{4}, 0.15 \%$; Peptone, 2\%; Glycerol, $1 \%(\mathrm{v} / \mathrm{v})$; Melanoidin, $1 \%(\mathrm{w} / \mathrm{v})$ was used. All the cultures used in this study were isolated from different sites of distillery effluent treatment plant. Pseudomonas putida (MTCC No. 2445) was used as a reference culture.

Collection of distillery effluent and soil samples: Distillery effluent was collected from effluent treatment plant. Main site was near by the oxidation ponds, where effluent was stored after anaerobic (primary) and aerobic (secondary) treatment before disposal. The colour of effluent was dark brown. Soil samples were aseptically collected from 6 sites of distillery located in Yamuna Nagar district of Haryana (India). Different sites of distillery plant were; effluent treatment plant (ETP), the site where the soil has been used since very long time for the disposal of effluent, new sites of disposal, nearby of running waste, dry samples and mud samples.

Preparation of melanoidins : Melanoidin was prepared following the method described by Adams $e t$ al. (2003) in which $0.05 \mathrm{Mol}$ of glucose (sugar, $9.00 \mathrm{~g}$ ) and $0.05 \mathrm{Mol}$ of glycine (amino acid, $3.75 \mathrm{~g}$ ) were dissolved in $20 \mathrm{ml}$ of distilled water. The carbonyl 
compound-amino acid mixture was placed in an oven at $125^{\circ} \mathrm{C}$. The mixture was heated for exactly $2 \mathrm{~h}$ without covering. The solid was transferred to a mortar and carefully ground to a fine powder.

\section{Isolation, purification and characterization of}

isolates : Isolation was done using Enrichment culture technique. Each soil sample (10 g) was suspended in sterile basal effluent media (90 ml) (Peptone, 2\%; Glycerol, $1 \% ; \mathrm{K}_{2} \mathrm{HPO}_{4}, 0.15 \% ; \mathrm{MgSO}_{4} .7 \mathrm{H}_{2} \mathrm{O}, 0.15 \%$ and Distillery effluent, $100 \%, \mathrm{v} / \mathrm{v}$ ) aseptically and incubated at temperature $37^{\circ} \mathrm{C}$. After $8 \mathrm{~d}, 50 \mathrm{ml}$ from each flask was discarded and fresh $50 \mathrm{ml}$ sterile basal effluent was added so that desirable microorganisms could grow and again incubated for 8 days. Isolated cultures were purified by streak plate method and further characterized by biochemical tests and staining methods. The morphology and Gram's stain was observed under light microscope. Biochemical tests such as Indole test, Methyl Red test, Citrate utilization, $\mathrm{H}_{2} \mathrm{~S}$ production, Gas production, Casein hydrolysis, Esculine hydrolysis, Nitrate reduction, Catalase test, Oxidase test, Urea hydrolysis, Tween 20 hydrolysis, Tween 40 hydrolysis, Tween 60 hydrolysis, Tween 80 hydrolysis and Acid production from dextrose, lactose and sucrose were determined.

Screening of isolates and optimization of process parameters : For inoculum preparation isolated microbes were cultured in King's Broth medium
(pH - 7.0) for $24 \mathrm{~h}$ at $37{ }^{\circ} \mathrm{C}$. Decolourisation assay was performed for screening. In primary screening isolates were screened against various concentrations of melanoidins $(0.2 \%-2.0 \%, \mathrm{w} / \mathrm{v})$. Decolourisation of treated effluent was measured as the decrease in optical density at $475 \mathrm{~nm}$ of the supernatant obtained upon centrifugation (10,000 rpm, $15 \mathrm{~min})$. Selected isolates from primary screening were further used for secondary screening. The degree of decolourisation was noted by spectrophotometer (Systronics PC based double beam spectrophotometer 2202).

Various parameters required for the decolourisation activity by the isolate $\mathrm{SAG}_{45}$ were optimized. These parameters included incubation temperature $\left(25{ }^{\circ} \mathrm{C}-55\right.$ $\left.{ }^{\circ} \mathrm{C}\right), \mathrm{pH}(5.0-9.0)$, effect of various concentrations of distillery effluent $(5 \%-100 \%, \mathrm{v} / \mathrm{v})$, supplementation of various carbon sources (maltose, sucrose, glucose, galactose, ribose, mannitol, fructose and xylose) at concentration of $2.0 \%(\mathrm{w} / \mathrm{v})$, supplementation of various nitrogen sources (peptone, beef extract, ammonium nitrate, yeast extract, ammonium sulphate and sodium nitrate) at concentration of $0.5 \%(\mathrm{w} / \mathrm{v})$, and supplementation of both selected carbon and nitrogen sources in combinations. The decolourisation ability of isolate $\mathrm{SAG}_{45}$ was checked at optimum conditions \{ media $\mathrm{MPB}$, temperature $37^{\circ} \mathrm{C}, \mathrm{pH} 8.0$, sucrose $(2.0 \%)$, peptone $(0.5 \%)\}$.

Table 1. Effect of bioremediated and raw effluent on germination of Vigna radiata.

\begin{tabular}{lll}
\hline Parameter (s) & Bioremediated effluent & Raw effluent \\
\hline \% germination & On $\mathbf{7}^{\text {th }}$ day & 23.30 \\
Germination speed & 96.60 & 2.33 \\
Emergence index & 10.70 & 1.40 \\
Peak value & 9.66 & 2.33 \\
\hline \% germination & 10.7 & 33.3 \\
Germination speed & On 15 th $^{\text {day }}$ & 3.33 \\
Emergence index & 100 & 2.0 \\
Peak value & 11.10 & 3.33 \\
Vigor index & 10.0 & 0.602 \\
Shoot length $(\mathrm{cm} / \mathrm{seed})$ & 11.10 & 0.072 \\
Root length $(\mathrm{cm} / \mathrm{seed})$ & 661 & 0.163 \\
Wet root weight (mg/seed) & 6.610 & 2.7 \\
Wet shoot weight (mg/seed) & 4.820 & 18.1 \\
Dry root weight (mg/seed) & 142.6 & 0.516 \\
Dry shoot weight (mg/seed) & 526 & 6.03 \\
Number of leaves & 57.100 & 0.166 \\
\hline
\end{tabular}

All values are average of three replicates. 


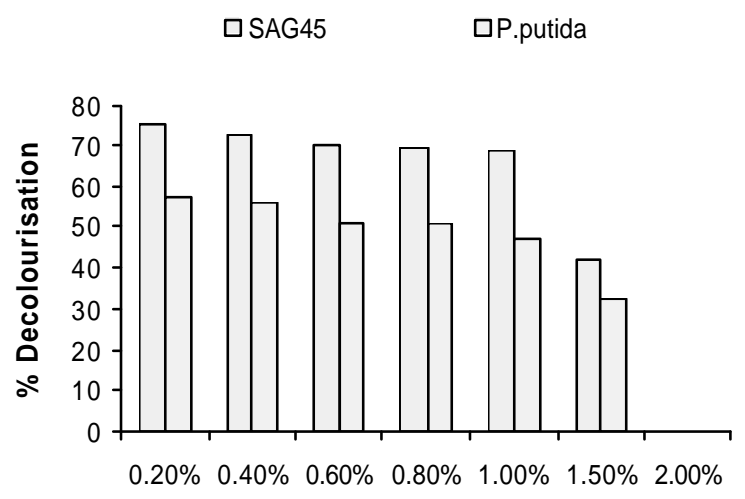

Melanoidin conc.

Fig.1. Decolourisation (\%) by isolate $S A G_{45}$ at different concentrations of melanoidin in $8 d$.

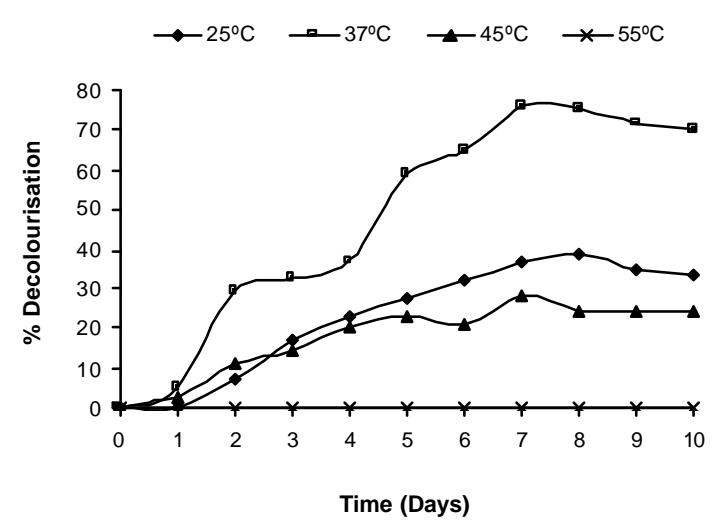

Fig.2. Effect of temperature on the decolourisation ability of isolate $\mathrm{SAG}_{45}$

The effect of raw and bioremediated effluents on seed germination of mung bean (Vigna radiata) was studied as described by Sharma et al., 2002. The seeds were surface sterilized with $0.1 \%$ Mercuric Chloride for 2 minutes, followed with repeated washings by using sterilized distilled water. An experimental design with 3 replicates and 30 seeds per petri dish were used. Seeds were spreaded on sterilized petri dishes lined with sterilized filter paper. The seeds were treated with equal volume $(10 \mathrm{ml})$ of raw and bioremediated distillery effluent. The Petri dishes were kept at room temperature. Germination measurements were made on the $7^{\text {th }}$ and $15^{\text {th }}$ day from the day of sowing.

The isolate was characterized and identified using standard methods with the help of MTCC, Institute of Microbial Technology (IMTECH), Chandigarh. It was found to be a strain of Pseudomonas putida and was given the accession MTCC 9782.

\section{RESULTS AND DISCUSSION}

Total 60 bacterial isolates were obtained and four efficient isolates were chosen after secondary screening. Out of which, isolate $\mathrm{SAG}_{45}$ showed $68.5 \%$ decolourisation

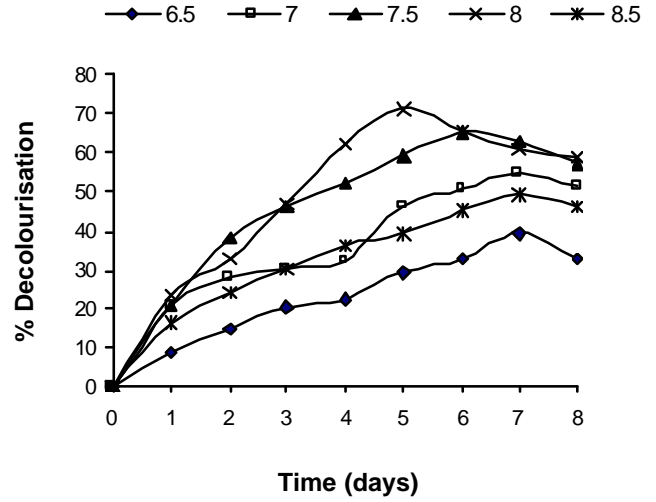

Fig.3. Effect of medium $\mathrm{pH}$ on the decolourisation ability of isolate $S A G_{4}$

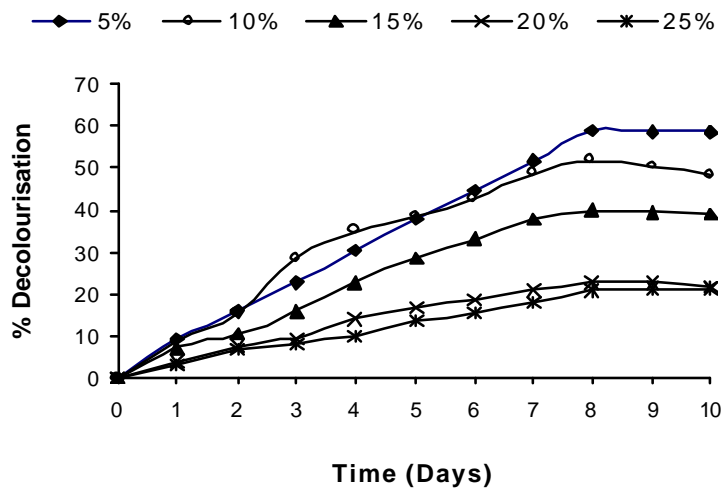

Fig.4. Effect of concentrations of distillery effluent.

activity when $1.0 \%(\mathrm{w} / \mathrm{v})$ melanoidin was used (Fig.1). Further increase in concentration from $1.0 \%(\mathrm{w} / \mathrm{v})$ of melanoidin abruptly decreases the decolourisation activity. The aim of using the different concentrations $(0.2 \%-2.0 \%)$ of melanoidin was to check the growth and decolourisation activity.

Effect of the incubation temperature: The effect of the incubation temperature on decolourisation in the range of $25^{\circ} \mathrm{C}-55^{\circ} \mathrm{C}$ showed that the optimal temperature was $37^{\circ} \mathrm{C}$ (Fig.2). Further increase of temperature upto $55^{\circ} \mathrm{C}$ inhibited the growth of this isolate. Ohmomoet al.(1988) examined optimum temperature of $35{ }^{\circ} \mathrm{C}-40{ }^{\circ} \mathrm{C}$ for maximum decolourisation yield. Sirianuntapiboon et al. (2004a) reported the strain No. BP103 showed higher decolourisation yield $(76.4 \pm 3.2 \%)$ when cultivated at $30^{\circ} \mathrm{C}$. The effect of $\mathrm{pH}$ on decolourisation in the range of $(5.0-$ 9.0) showed the highest decolourisation activity at $\mathrm{pH}$ 8.0 (Fig.3). Ohmomo et al. (1988) examined pH range of 4.0 - 4.5 for maximum decolourisation yield. Sirianuntapiboon et al. (2004b) examined pH 6.0 for maximum decolourisation for yeast strain of Citeromyces sp. WR-43-6. Adikane et al. (2006) showed maximum decolourisation at $\mathrm{pH} 6.0$; however significant 
decolourisation was observed in the $\mathrm{pH}$ range of 5.0 8.0. Melanoidin decolourisation (67\%) was maximum at pH 7.0 (Mohana et al., 2007). Sirianuntapiboon et al. (2004a) have reported higher decolourisation activity by an acetogenic strain in the $\mathrm{pH}$ range of 5.0 - 7.0.

The effect of various concentrations of distillery effluent in the range of $5.0 \%-100 \%(\mathrm{v} / \mathrm{v})$ showed that decolourisation increased with decrease in the concentration of distillery effluent. As obvious from Fig. 4, the maximum decolourisation (58.9\%) showed by the isolate $\mathrm{SAG}_{45}$ was at $5.0 \%$ concentration whereas it reduced to $20.8 \%$ at concentration of $25 \%$.

The effects of carbon sources on decolourisation activity of $\mathrm{SAG}_{45}$ tested in MPB that contained various kinds (maltose, sucrose, glucose, galactose, ribose, mannitol, fructose and xylose) of carbon sources $(2.0 \%)$ showed the high level of decolourisation yields (78.8\% and 54.4\%) in 5 days incubation when the carbon source was sucrose and ribose, respectively (Fig.5). Sirianuntapiboon et al. (2004a) reported glucose (3.0\%) and fructose $(2.0 \%)$ as a carbon source that showed highest decolourisation of $55.0 \pm 1.2 \%$ and $54.8 \pm 0.71 \%$ within 5 days cultivation. Ohmomo et al. (1988) reported Lactobacillus hilgardii that showed decolourisation of $28 \%$ when glucose $(1.0 \%)$ was used as carbon source. Sirianuntapiboon etal. (2004 b)reported that Citeromyces sp. WR-43-6 showed maximum decolourisation with glucose at concentration of $2.0 \%$ within 8 days of incubation. Sirianuntapiboon (1999) isolated two strains of acid forming bacteria. Strain No. BP103 showed maximum decolourisation with maltose $(87.3 \%)$ or fructose $(77.84 \%)$ and for strain No. 13A, activity was $79.5 \%$ with galactose or $82.5 \%$ with fructose within 5 days of cultivation. Mohana et al. (2007) reported the consortium DMC that decolourised (67\%) the anaerobically treated distillery spent wash most effectively in presence of basal salts and glucose $(0.5 \%)$ and hence supplementation of glucose appeared to be necessary for decolourisation.Fructose, sucrose and galactose were found to be fairly good substrates allowing 60\% - 67\% decolourisation and 40\% - 48\% COD reduction. Starch was relatively poor co-substrate, aiding $55 \%$ decolourisation.

Effect of nitrogen sources : The effect of nitrogen sources on decolourisation activity tested in MPB that contained various kinds (peptone, beef extract, ammonium nitrate, yeast extract and ammonium sulphate) of nitrogen sources $(0.5 \%)$ showed the highest decolourisation yield $(76.9 \%)$ within 5 days using peptone (Fig.6). Sirianuntapiboon et al. (2004 a) showed highest decolourisation of $55.8 \pm 0.33 \%$ and $54.0 \pm 0.81 \%$ within 5 days cultivation using yeast extract and peptone $(0.2 \%)$ as a nitrogen source. Sirianuntapiboon et al. (2004b) examined that the inorganic nitrogen source was

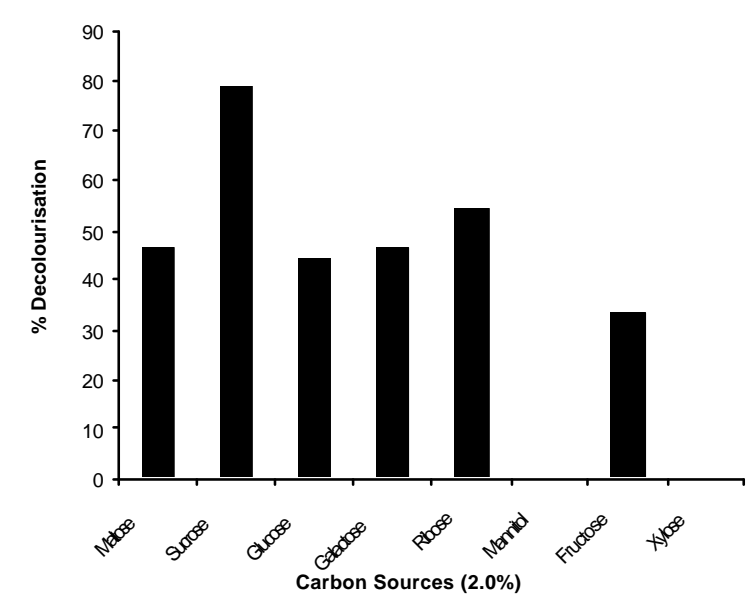

Fig.5. Effects of carbon sources on the decolourisation activity.

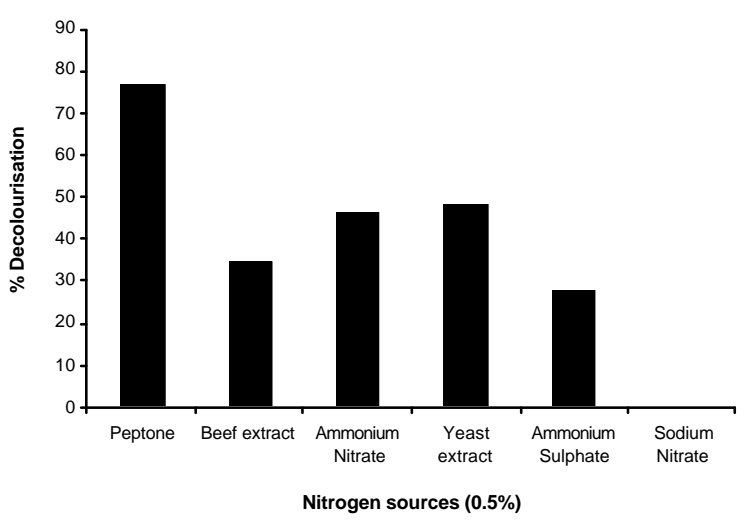

Fig.6. Effects of nitrogen sources on the decolourisation activity.

more effective than organic nitrogen source and the maximum decolourisation activity was $35.9 \%$ with $\mathrm{NaNO}_{3}$ $(0.1 \%)$ within 8 days of incubation. Sirianuntapiboon (1999) isolated two strains that showed highest decolourisation of $82.0 \%$ and $80.5 \%$ with yeast extract within 5 days. Adikane et al. (2006) observed the maximum decolourisation of $81 \%$ in the absence of any nitrogen source after 18 days of incubation. Mohana et al. (2007) found inhibitory effect of both the organic and inorganic nitrogen sources on melanoidin decolourisation by bacterial consortium.

In another experiment supplementation of both selected carbon $(2.0 \%, \mathrm{w} / \mathrm{v})$ and nitrogen $(0.5 \%, \mathrm{w} / \mathrm{v})$ source was used in the MPB. Four experimental setup included sucrose (+ beef extract / ammonium nitrate / yeast extract / peptone), glucose ( + beef extract / ammonium nitrate / yeast extract / peptone), maltose (+ beef extract / ammonium nitrate / yeast extract / peptone), and galactose (+ beef extract / ammonium nitrate / yeast extract / peptone). The isolate $\mathrm{SAG}_{45}$ gave the maximum decolourisation yield $(79.5 \%)$ within 4 days of cultivation with the supplementation of combination of sucrose $(2.0 \%)$ and peptone $(0.5 \%)$ (Fig.7). In another experiment with fructose $(2.0 \%)$ and yeast extract $(0.5 \%)$, the strain No. 13A and strain No. BP103 gave the maximum 


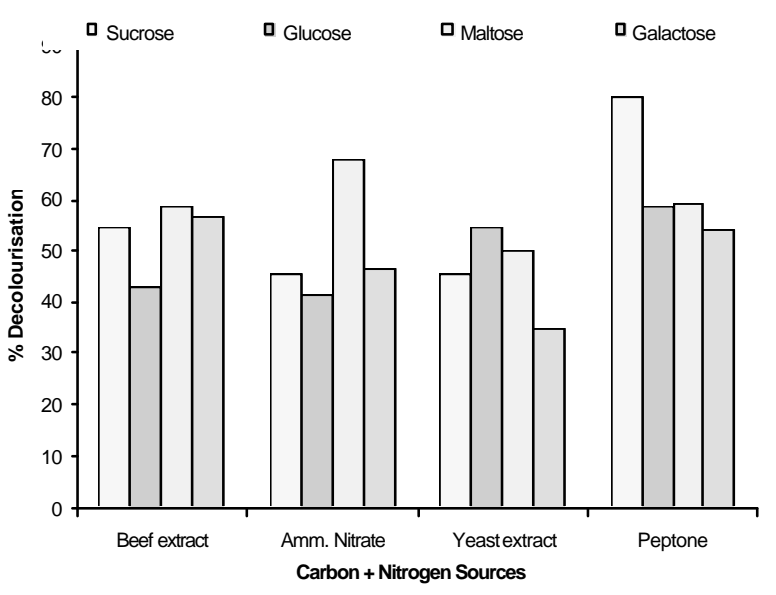

Fig.7. Combined effect of both selected carbon and nitrogen sources on the Decolourisation activity.

decolourisation yield of $90.0 \%$ and $96.75 \%$ within 4 days (Sirianuntapiboon, 1999).

The isolate $\mathrm{SAG}_{45}$ showed the highest decolourisation yield $(79.5 \%)$ when it was cultured at $37^{\circ} \mathrm{C}$ for 4 days with the supplementation of sucrose $(2.0 \%)$ and peptone $(0.5 \%)$. Sirianuntapiboon et al. (2004 a) reported glucose $(3.0 \%)$ as a carbon source that showed highest decolourisation of $55.0 \pm 1.2 \%$ within 5 days cultivation. Whereas isolate $\mathrm{SAG}_{45}$ showed maximum decolourisation $(78.8 \%)$ with sucrose $(2.0 \%)$. Sirianuntapiboon et al. (2004a) reported yeast extract and peptone $(0.2 \%)$ as a nitrogen source that showed highest decolourisation of $55.8 \pm 0.33 \%$ and $54.0 \pm 0.81 \%$ within 5 days cultivation. However, isolate $\mathrm{SAG}_{45}$ - showed $76.9 \%$ decolourisation with peptone $(0.5 \%)$ within 5 days. Tondee et al. (2008) showed the highest decolourisation $(68.12 \%)$ with the medium containing glucose $(2.0 \%)$ and yeast extract $(0.4 \%)$ at $30{ }^{\circ} \mathrm{C}$ within 7 days of culture.

The seeds treated with bioremediated effluent showed initiation of germination on $3^{\text {rd }}$ day whereas no germination was observed in the seeds treated with raw effluent. It has been observed that the toxic components of any industrial waste on coming in contact with germinating seed or plant may enter the body system resulting in ultimate damage to seed and seedling growth (Sharma et al., 2002). During the present study it was observed that the effluent before treatment was very toxic due to the presence of melanoidins. These constituents are phytotoxic at higher concentration and inhibited the growth of seeds but after bioremediation the toxicity of effluent decreases. The various parameters studied on $7^{\text {th }}$ day showed \% germination $(96.6 \%, 23.3 \%)$; germination speed $(10.7,2.33)$; emergence index $(9.66,1.40)$; and peak value $(10.7,2.33)$ on treatment with bioremediated and raw effluent The plant growth measurements included shoot length, root length, wet shoot weight, wet root weight, dry shoot weight, dry root weight and vigor index were noted in $15^{\text {th }}$ day old seedlings (Table 1). Germination studies showed $100 \%$ germination in seeds treated with bioremediated effluent and $33.3 \%$ in seeds treated with raw effluent in $15^{\text {th }}$ day. Germination speed $(11.1,3.33)$, emergence index $(10.0,2.0)$, peak value $(11.1,3.33)$ and vigor index $(661,0.602)$ was for seeds treated with bioremediated and raw effluent respectively. The shoot length $(6.61 \mathrm{~cm})$, root length $(4.82 \mathrm{~cm})$, wet root weight $(142.6 \mathrm{mg})$, wet shoot weight $(526 \mathrm{mg})$, dry root weight $(57.1 \mathrm{mg})$, dry shoot weight $(23.86 \mathrm{mg})$ and no. of leaves (1.766) were highest in bioremediated effluent.

Reduction in seed germination and seedling growth treated with raw effluent may be due to higher amount of dissolved solids present in effluent. The dissolved solids may prevent the germination by contribution to salinity of the solute absorbed by the seeds before germination (Medhi et al., 2008). According to Suresha and Puttaiah (2006) the higher concentration of dissolved salts and cations are responsible for inhibition of the seed germination and related parameters. Therefore hereby we can conclude that raw effluent is rich in dissolved salts, cations and melanoidin which is toxic for seed germination whereas bioremediated effluent have depletion of these salts, cations and melanoidin due to which $100 \%$ germination occurred in seeds treated with bioremediated effluent.

\section{Conclusion}

Bacterial isolate $\mathrm{SAG}_{45}$ appears to be very efficient strain of Pseudomonas putida and has the ability to decolourise distillery effluent. It might be suitable microorganism which could be applied in the conventional bioremediation plant for the purpose of colour removal of effluents.

\section{ACKNOWLEDGEMENTS}

The authors are very thankful to University Grant Commission for providing financial assistance for research project in the form of Rajiv Gandhi National Fellowship (JRF) to AR.

\section{REFERENCES}

Adams, A., Tehrani, K.A., Kersiene, M., Venskutonis, R., and Kimpe, N.D. (2003). Characterization of model melanoidins by the thermal degradation profile. Journal of Agricultural and Food chemistry, 51: 4338 - 4343.

Adikane, H.V., Dange, M.N. and Selvakumari, K. (2006). Optimization of anaerobically digested distillery molasses spent wash decolourization using soil as inoculum in the absence of additional carbon and nitrogen source. Bioresource Technology, 97: 2131- 2135.

Chandra, R. (1993). Development of indigenous technology (Microbial strains) for the removal of sulfur compounds and colour from distillery effluent. Annual Progress Report, Industrial Toxicology Res Centre, Lucknow.

Medhi, U.J., Talukdar, A.K. and Deka, S. (2008). Effect of pulp and paper mill effluent on seed germination and seedling growth of mustard (Brassica campestris), pea (Pisum sativam), and rice (Oryza satival) seeds. Pollution Research, 27: 437 - 442.

Mohana, S., Desai, C. and Madamwar, D. (2007). Biodegradation and decolourization of anaerobically treated 
distillery spent wash by a novel bacterial consortium. Bioresource Technology, 98: 333 - 339.

Naik, N.M., Jagdeesh, K.S. and Alagawadi, A.R. (2008) Microbial decolorization of spentwash: a review. Indian Journal of Microbiology, 48: 41 - 48.

Ohmomo, S., Daengsubha, W., Yoshikawa, H., Yui, M., Nozaki, K., Nakajima, T. and Nakamura, I. (1988). Screening of anaerobic bacteria with the ability to decolorize molasses melanoidin. Agricultural and Biological Chemistry, 52: 2429 - 2435.

Pant, D. and Adholeya, A. (2007). Biological approaches for treatment of distillery wastewater: a review. Bioresource Technology, 98: 2321 - 2334.

Satyawali, Y. and Balakrishnan, M. (2007). Removal of color from biomethanated distillery spentwash by treatment with activated carbons. Bioresource Technology, 98: 2629 - 2635.

Sharma, V., Sharma, R. and Sharma, K.D. (2002). Distillery effluent on seed germination, early seedling and pigment content of sugarbeet (Beta vulgaris Linn. Var. MezzanauPoly). Journal of Environmental Biology, 23: 77 - 80.
Sirianuntapiboon, S. (1999). Selection of acid forming bacteria having decolourization activity for removal of color substances from molasses waste water. Thammasat International Journal of Science and Technology, 4: 1 - 12. Sirianuntapiboon, S., Phothilangka, P. and Ohmomo, S. (2004a). Decolourization of molasses wastewater by a strain No. BP103 of acetogenic bacteria. Bioresource Technology, 92: $31-39$.

Sirianuntapiboon, S., Zohsalam, P. and Ohmomo, S. (2004b). Decolourization of molasses wastewater by Citeromyces sp. WR-43-6. Process Biochemistry, 39: 917 - 924.

Suresha, G. and Puttaiah, E.T. (2006). Effect of distillery effluent on seed germination and seedling growth of paddy \{Oryza sativa (L.) Var.I.R.64\}. Geobios., 33: 129 -132.

Tondee, T. and Sirianuntapiboon, S. (2008). Decolorization of molasses wastewater by Lactobacillus plantarum No. PV711861. Bioresource Technology, 99: 6258 - 6265. 